\title{
BIOLOGICAL ACTION OF PLANT EXTRACTS ON A FUNGAL PLANT BIOSTIMULANT STRAIN OF TRICHODERMA VIRIDE
}

\author{
ŞESAN Tatiana Eugenia ${ }^{1,4,5}{ }^{*}$, ENACHE Elena $^{1}$, IACOMI Beatrice Michaela ${ }^{2}$, \\ OPREA Maria ${ }^{3}$, OANCEA Florin ${ }^{4}$, IACOMI Cristian ${ }^{2}$
}

\begin{abstract}
The antifungal activity of nine plant extracts manufactured by Hofigal Import Export S.A. Romania against the biocontrol fungal agent Trichoderma viride Pers. (isolate Tv 82) was assessed in vitro for the first time in Romania. In general, the development (mycelial growth and sporulation) was not inhibited by the six plant extracts (Satureja hortensis, Achillea millefolium, Allium sativum, Mentha sp., Hyssopus officinalis, Artemisia dracunculus 'Sativa'), with three exceptions (Rosmarinus officinalis, Valeriana officinalis, Tagetes patula), applied in a concentration of $20 \%$. Among these, the extract of Tagetes patula has inhibited the Tv 82 development, applied as lower concentrations (10\% and 5\%), efficacy being $54.3 \%$ and 50\%, respectively. In addition, the tested plant extracts of Satureja hortensis, Achillea millefolium, Mentha sp. proved stimulative effect on Tv 82 development. This approach add to the early studies on the selectivity of Trichoderma spp. to chemicals used in plant protection, new data referring to the use of antagonistic fungi, like Trichoderma spp., as a protective mean against phytopathogens. Also, these data sustain the possibility of applying plant extracts as an alternative in plant protection or to apply together chemical (pesticides) and biological means (plant extracts) especially to protect ecological crops, as vegetables, medicinal plants a.o.
\end{abstract}

Keywords: Trichoderma viride, plant extracts, biocontrol

\section{Introduction}

Trichoderma species (Ascomycota, Pezizomycotina, Sordariomycetes, Hypocreales, Hypocreaceae, Index Fungorum, Kirk, 2015) are effective biocontrol agents against many plant pathogens. The antifungal activity of nine plant extracts manufactured by Hofigal S.A. against a plant biostimulant strain of Trichoderma viride Pers., isolate Tv 82, from the Collection of Research - Development Institute for Plant Protection (RDIPP) Bucharest, was assessed in vitro, based on the literature considerations (Harman et al. 2004, 2012, Schuster \& Schmoll 2010, Hermosa et al. 2012, Saba et al. 2012, Sofo et al. 2012 a.o.).

\footnotetext{
${ }^{1 *}$ University of Bucharest, Biology Faculty, Department of Botany \& Microbiology, 1-3, Intr. Portocalelor, Sector 6, 060101 - Bucureşti, Romania, e-mail: tatianasesan@yahoo.co;

${ }^{2}$ University of Agricultural Sciences and Veterinary Medicine Bucharest, Faculty of Agriculture;

${ }^{3}$ Research - Development Institute for Plant Protection Bucharest;

${ }^{4}$ National Research \& Development Institute for Chemistry and Petrochemistry (ICECHIM) Bucharest;

${ }^{5}$ Academy of Agricultural Sciences and Forestry
} 


\section{Material and methods}

Fungal material: one isolate of Trichoderma viride (Tv 82) from the Collection of RDIPP Bucharest.

Biological material: nine hydroalcoholic plant extracts from: Achillea millefolium L., Allium sativum L., Artemisia dracunculus L. 'Sativa', Hyssopus officinalis L., Mentha sp., Rosmarinus officinalis L., Satureja hortensis L., Tagetes patula L., Valeriana officinalis L., prepared by S.C. Hofigal Import Export Bucharest Romania (from fresh biomass as stems, leaves, flowers, sprouts, bulbs).

In vitro tests: the method of including plant extracts in PDA medium at $20 \%$, $10 \%$, and $5 \%$ concentrations, in three replicates for each extract, has been used. Discs of $5 \mathrm{~mm}$ from 7 days $T$. viride Tv 82 cultures have been placed in the Petri plates with plant extracts included in the PDA agarized medium.

Evaluation of biological action has been achieved by the following parameters: inhibition rate of mycelial growth $(\mathrm{mm})$ compared to untreated control (\%); effective concentrations EC50 and EC90, the concentrations which reduced mycelial growth by 50 and, respectively, $90 \%$ ).

\section{Results and discussion}

Development (mycelial growth and sporulation) of $T$. viride, isolate $\operatorname{Tv} 82$, was not inhibited by the six plant extracts (S. hortensis, A. millefolium, A. sativum, Mentha sp., H. officinalis, A. dracunculus 'Sativa'), with three exceptions ( $R$. officinalis, $V$. officinalis, T. patula) applied at $20 \%$ concentration (Figs 1,2).

Among these, the extract of Tagetes patula has inhibited the Tv 82 development, applied as lower concentrations (10\% and 5\%), inhibition being $54.3 \%$ and $50 \%$, respectively. In addition, some of the tested plant extracts (Satureja hortensis, Achillea millefolium, Mentha sp.) proved a stimulative effect on Tv 82 development.

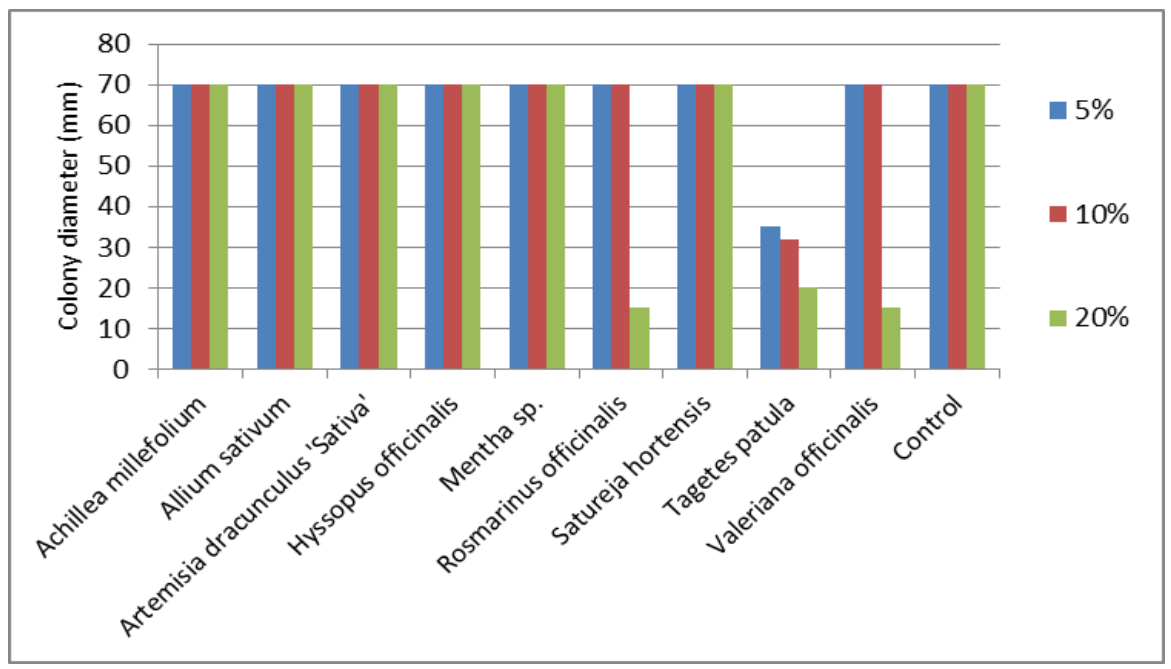

Fig. 1. Colony diameter ( $\mathrm{mm}$ ) of Trichoderma viride, isolate Tv 82, after in vitro treatments with plant extracts 


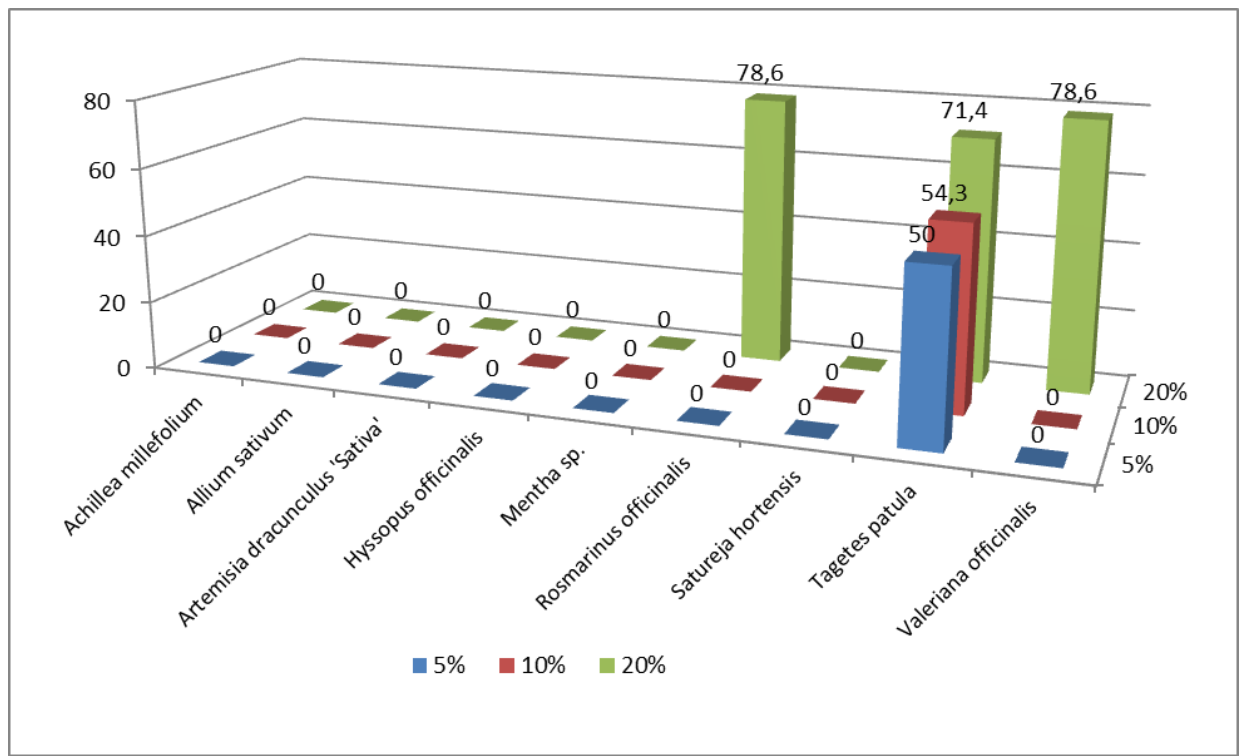

Fig. 2. Biological action of the in vitro plant extracts treatments on the development of Trichoderma viride, isolate Tv82

Table 1

In vitro level of sensitivity for Trichoderma viride, isolate Tv 82

\begin{tabular}{lcc}
\hline \multicolumn{1}{c}{$\begin{array}{c}\text { Variant } \\
\text { (plant extract) }\end{array}$} & \multicolumn{2}{c}{ Level of sensitivity (\%) } \\
\cline { 2 - 3 } 1. Rosmarinus officinalis & EC50 $(\%)$ & EC90 $(\%)$ \\
2. Valeriana officinalis & 15.9 & 23.0 \\
3. Tagetes patula & 23.3 & 36.4 \\
4. Satureja hortensis & 5.0 & 33.1 \\
5. Achillea millefolium & $>20$ & $>20$ \\
6. Allium sativum & $>20$ & $>20$ \\
7. Mentha sp. & $>20$ & $>20$ \\
8. Hyssopus officinalis & $>20$ & $>20$ \\
9. Artemisia dracunculus 'Sativa' & $>20$ & $>20$ \\
\hline
\end{tabular}

The level of sensitivity of Tv 82 isolate to the tested plant extracts has been also evaluated and the results were expressed as effective concentrations EC50 and EC90. As shown in the Table 1, with regard to mycelial growth response to plant extracts, $\mathrm{Tv}$ 82 isolate was no sensitive to $S$. hortensis, A. millefolium, Allium sastivum, Mentha sp., H. officinalis and A. dracunculus 'Sativa' extracts, with EC90 values over $20 \%$. By contrast, the tested isolate seems to be more sensitive to T. patula, R. officinalis and $V$. officinalis extracts, with EC90 values ranging between $23.3 \%$ and $36.4 \%$.

Further studies are needed to assess the possibility of combining plant extracts and biocontrol agents to provide a novel approach for inhibiting the pathogenic fungi in nutraceutical crops in Romania. 


\section{Conclusions}

Our present approach add to the early studies on the selectivity of Trichoderma spp. to chemicals used in crop treatments (Şesan et al. 1998, Şesan 2002) new data referring to the use of plant biostimulant fungi, like Trichoderma spp., as a new mean for crop treatments. Also, these data sustain the possibility of applying plant extracts as an alternative for crop treatments, especially on organically managed vegetables or medicinal/nutraceutical plants.

Acknowledgments. This research was financially supported by the projects PNII-PT-PCCA-2013-4-0995 (MAIA) and PN-II-PT-PCCA-2013-4-0846 (CERES).

\section{References}

Harman, G.E., Howell, A., Chet, I. \& Lorito, M. (2004). Trichoderma species opportunistic, avirulent plant symbionts. Nature reviews, Microbiology, 2(1), 43-56.

Harman, G.H., Herrera-Estrella, A.H., Horwitz, A. \& Lorito, M. (2012). Special issue: Trichoderma - from basic biology to biotechnology, Microbiology, 158, 1-175.

Hermosa, R., Viterbo, A., Chet, I. \& Monte, E. (2012). Plant-beneficial effects of Trichoderma and of its genes. Microbiology, 158, 17-25.

Kirk, P. (2015). Index Fungorum database. Retrieved November 13, 2015, from http://www.indexfungorum.org

Saba, H., Vibhash, D., Manisha, M., Prashant, K.S., Farhan, H. \& Tauseaf, A. (2012). Trichoderma - a promising growth stimulator and biocontrol agent, Mycosphere, 3(4), 524-531. DOI 105943/mycosphere/3/4/14.

Schuster, A. \& Schmoll, M. (2010). Biology and biotechnology of Trichoderma, Applied Microbiology and Biotechnology, 87, 787-799. DOI 10.1007/s00259010-2532-1.

Sofo, A., Nuzzaci, M., Vitti, A., Tatarani, G. \& Scopa, A. (2014). Control of biotic and abiotic stresses in cultivated plants by the use of biostimulant microorganisms. In P. Ahmed, M.R. Wani, M.M. Azooz \& L-S.P. Tran (eds.). Improvement of crops in the Era of Climatic Changes. vol. I (pp. 109-110). New York: Springer Science + Business Media.

Şesan, T.E., Oprea, M. \& Ciurdărescu, M. (1998). In vitro biological action of some pesticides manufactured by Oltchim S.A. on the antagonistic fungi (in Romanian), 1997, Analele ICPP Bucureşti, 29, 181-191.

Şesan, T.E. 2002. In vitro biological action of pesticides on Trichoderma viride. 7 th Workshop of the IOBC/WPRS "Influence of abiotic and biotic factors on biocontrol agents", 22-26 May 2002, Kusadashi, Turkey, IOBC/WPRS Bulletin 25(10), 415-418. 